\title{
El dolor orofacial
}

$\mathrm{P}$ aralelamente al progresivo cambio en el enfoque diagnóstico y terapéutico de los cuadros clínicos no mortales que cursan con dolor y limitación funcional de larga duración, desde modelos basados en tradicionales conceptos biomédicos mecanicistas (causa-efecto) hacia una concepción biopsicosocial con abordaje multidisciplinar e interdisciplinar que ha experimentado la Medicina y el resto de las especialidades de la salud, el dolor orofacial también ha seguido esta misma transición de forma aún más significativa, ya que el cambio no se ha limitado a un avance científico lineal, sino que ha experimentado un cambio radical en los principales axiomas científicos sobre los que se asienta el manejo de estos cuadros de disfunción craneomandibular y dolor orofacial. Los conceptos erróneos que en los años 30 del siglo pasado dieron lugar al conocido como "síndrome de Costen" y que tuvieron como consecuencia una orientación exclusivamente estructural mecanicista de corrección de las "maloclusiones dentarias" han quedado superados con los conocimientos que han aportado la Medicina y la Odontología Basada en la Evidencia.

En la actualidad, los cuadros clínicos de dolor craneofacial crónico tienen un abordaje diagnóstico y terapéutico similar al resto de las entidades clínicas médicas de parecidas características. Aunque en muchas ocasiones no es posible conseguir una curación absoluta de la patología (Restitutio Ad Integrum), sí podemos hacer un manejo terapéutico orientado a aliviar el dolor, recuperar en lo posible la funcionalidad y permitir que el paciente retome su actividad diaria personal y profesional. Para ello es necesario que colabore de forma integrada un equipo de profesionales de la salud que tengan un conocimiento adecuado de las patologías que afectan al aparato masticatorio, la cara, la cabeza y el cuello. Ello permitirá llegar a un diagnóstico (o diagnósticos) correcto y preparar un plan de tratamiento dirigido a corregir en lo posible la etiología que ha provocado el cuadro, no a paliar la sintomatología dolorosa o disfuncional.

En este sentido, los dentistas (médicos estomatólogos y odontólogos) juegan un papel primordial en este equipo multidisciplinar al ser los profesionales de la salud que tienen un conocimiento más profundo de la fisiología y la patología del sistema estomatognático y las estructuras vecinas. Es importante que los especialistas en odontoestomatología reciban una formación médica adecuada, cosa que, desgraciadamente, hoy no sucede y se integren en sociedades científicas que abarquen contenidos de interés común. Una de las más importantes en este sentido es la Sociedad Española del Dolor. Desde hace algunos años se están produciendo acercamientos entre esta sociedad y la Sociedad Española de Disfunción Craneomandibular y Dolor Orofacial, que es la sociedad científica que engloba a los dentistas interesados en el estudio y tratamiento de los cuadros clínicos que cursan con dolor en la boca, la cara, la cabeza y el cuello.

Un ejemplo del interés creciente que esta especialidad de dolor craneofacial está despertando es el monográfico sobre este tema que próximamente publicará la Revista de la Sociedad Española del Dolor y el artículo de revisión que se publica en este número.

Espero que el camino que se ha iniciado progrese en el futuro con la incorporación a la Sociedad Española del Dolor de nuevos profesionales de otras disciplinas de la salud (fisioterapeutas, psicólogos, enfermeros, terapeutas ocupacionales, trabajadores sociales, etc.) y que la SED realmente sea un punto de encuentro de todos los interesados en el tratamiento del dolor. 